\title{
Decomposing socioeconomic inequality for binary health outcomes: an improved estimation that does not vary by choice of reference group
}

\author{
Vasoontara Yiengprugsawan*, Lynette LY Lim, Gordon A Carmichael, Keith BG Dear, Adrian C Sleigh
}

\begin{abstract}
Background: Decomposition of concentration indices yields useful information regarding the relative importance of various determinants of inequitable health outcomes. But the two estimation approaches to decomposition in current use are not suitable for binary outcomes.

Findings: The paper compares three estimation approaches for decomposition of inequality concentration indices: Ordinary Least Squares (OLS), probit, and the Generalized Linear Model (GLM) binomial distribution and identity link. Data are from the Thai Health and Welfare Survey 2003. The OLS estimates do not take into account the binary nature of the outcome and the probit estimates depend on the choice of reference groups, whereas the GLM binomial identity approach has neither of these problems.

Conclusions: The GLM with binomial distribution and identity link allows the inequality decomposition model to hold, and produces valid estimates of determinants that do not vary according to choice of reference groups. This GLM approach is readily available in standard statistical packages.
\end{abstract}

\section{Findings}

Over the past decade, inequality measures have been adapted from the field of economics and subsequently applied to the study of health inequalities. The concentration index is now widely used to study inequality in the health sector [1-3]. One of its important features is a mathematical property that allows the overall concentration index to be decomposed into a linear combination of concentration indices of its determinants $[4,5]$. Quantifying contributions of determinants of an overall health inequality has been undertaken for many health outcomes [6-12].

Decomposition estimation was originally designed for cases where the health outcome was continuous using Ordinary Least Squares (OLS) regression. The OLS assumes normality of the outcome variable and implicitly assumes also that the mean outcome is a linear combination of the determinants. Since then another approach, used for the case where the health outcome

\footnotetext{
* Correspondence: vasoontara.yieng@anu.edu.au
The Australian National University, National Centre for Epidemiology and

* Correspondence: vasoontara.yieng@anu.edu.au Population Health, ANU College of Medicine, Biology \& Environment, Canberra ACT 0200, Australia
}

(c) 2010 Yiengprugsawan et al; licensee BioMed Central Ltd. This is an Open Access article distributed under the terms of the Creative Commons Attribution License (http://creativecommons.org/licenses/by/2.0), which permits unrestricted use, distribution, and reproduction in any medium, provided the original work is properly cited. on the use of a probit model with marginal effects [2], and Hosseinpoor et al [8] modified this approach slightly, using a logit instead of a probit analysis. This extension of the decomposition method to deal with binary outcomes is very appealing, because health sector outcomes are often binary.

Decomposition methodology has long been used to examine discrimination in the labor market $[13,14]$. The impact of choices of reference groups on parameter estimates for wage discrimination studies was first noted by Jones [15] and then addressed by Oaxaca and Ransom [16] in the context of multiple sets of categorical variables. However, these wage discrimination papers deal with continuous outcomes and provide no information on how to manage reference groups for the binary outcomes often encountered in health studies.

Here we: 1) compare the existing estimation approaches for decomposition of inequality for binary health outcomes; 2) show that the decomposition of a binary outcome using probit analysis can lead to different results with different choices of reference group; and 3) introduce an alternative approach that uses the 
Generalized Linear Model (GLM) with binomial distribution and identity link.

\section{Methods}

\section{Data source and variables}

We used data from the Thai Health and Welfare Survey of 2003 conducted by the National Statistical Office. In this survey every available member of a sampled household aged 15 years or older was interviewed, a total of 37,202 individuals from 19,952 households.

\section{Outcome variable}

The health outcome studied was recent morbidity, a binary variable. The English translation of the relevant survey question was: "Have you been ill or not feeling well during the past one month?"

\section{Socioeconomic rank}

Monthly adult-equivalent household income was used as the measure of socioeconomic status. For Thailand, empirical studies suggest weighting each child aged under 15 as 0.5 of an adult and allowing for economies of scale applying to any household with more than one member by raising adult-equivalent household size to the power of 0.75 [17].

\section{Determinants}

Three categorical health determinants were examined: eight age-sex groups (males aged 15-29 years, males aged 30-44 years, males aged 45-59 years, males aged 60 years or older, females aged 15-29 years, females aged 30-44 years, females aged 45-59 years, females aged 60 years or older); four levels of education (no education, primary, high school, higher education); and five areas of residence (Bangkok, Central, North, Northeast, South).

Measurement of inequalities in health as a concentration index $(C)$ has primarily drawn on the literature on income inequality measures $[3,18,19]$. The concentration index can be written in various ways, but one of the most cited is that proposed by Kakwani et al. [1]:

$$
C=\frac{2}{n \mu}\left[\sum_{i=1}^{n} h_{i} R_{i}\right]-1
$$

Where $h_{i}$ is the variable of interest for the $i^{\text {th }}$ person; $\mu$ is the mean or proportion of $h ; n$ is the number of persons; and if the $n$ individuals are ranked according to their socioeconomic status, beginning with the most disadvantaged, then $R_{i}$ is their relative rank, $i-0.5 / n$. When there is no inequality (or when inequality is balanced and opposite for equal fractions of the incomeranked population), the concentration index equals 0 . If the variable of interest is concentrated at a lower (or higher) socioeconomic level, the concentration index becomes negative (or positive).
Three approaches to the decomposition of a binary health outcome are compared: Ordinary Least Squares (OLS), marginal effects from probit analysis, and Generalized Linear Model (GLM) specifying binomial distribution and identity link [20].

\section{Ordinary Least Squares (OLS)}

Wagstaff et al [5] demonstrate that the concentration index of a continuous health outcome can be decomposed into the contributions of individual determinants. In this case, a linear additive relationship between outcome variables $h_{i}$ and the contributions of $k$ determinants is appropriate:

$$
h_{i}=\alpha+\sum_{k} \beta_{k} x_{k i}+\varepsilon_{i}
$$

and OLS regression is applied to estimate the $\beta_{k}$ 's. By substituting from Equation 2 into Equation 1, the overall concentration index $(\mathrm{C})$ can be rewritten as a linear combination of the concentration indices of the determinants, plus an error term (Equation 3):

$$
C=\sum_{k}\left(\frac{\beta_{k} \bar{x}_{k}}{\mu}\right) C_{k}+\frac{G C_{\varepsilon}}{\mu}
$$

$\beta_{k}$ are the coefficients from regressions of the health outcome on each $k$ determinant, $\bar{x}_{k}$ is the mean or proportion of each $k$ determinant, $\mu$ is the mean or proportion of the health outcome, and $C_{k}$ is the concentration index for the $k t h$ determinant calculated using Equation 1 , replacing the health outcome $\left(h_{i}\right)$ with the determinant $\left(\mathrm{x}_{k i}\right), G C_{\varepsilon}$ is the generalized concentration index for the error term.

\section{Probit estimates}

Health sector variables are seldom continuous and are often binary (e.g., ill, not ill). Van Doorslaer [2] modified Wagstaff's method for use in such non-linear settings. The essential modification was to estimate the $\beta_{k}$ 's that go into Equation 3 from a probit regression instead of OLS regression. More specifically, van Doorslaer recommends the use of marginal effects of the $\beta_{k}$ 's. The World Bank technical notes on non-linear estimation suggest generating marginal effects using the Stata command: dprobit y x [21]. Marginal effects can also be calculated using the $\mathbf{m f x}$ command after running the non-linear model. By default, the marginal effects of each explanatory variable are evaluated at sample means, and in large samples the sample mean approximates the overall mean of the marginal effects [22].

\section{Generalized Linear Models (GLM)}

The GLM is an extension of the linear modelling process that allows models to be fitted to data that follow 
probability distributions other than the normal distribution, such as the binomial distribution [23]. The GLM relaxes the assumption of homogeneity of variances that is usual in linear models and enlarges the class of linear OLS models in two ways:

(i) the distribution of $\mathrm{Y}$ for fixed $\mathrm{x}$ is assumed to be from an exponential family of distributions [24], which includes important families such as the normal and binomial distributions;

(ii) the relationship between the mean of $\mathrm{Y}$ and a linear combination of $x$ 's is specified by a link function.

The link function connects the probability distribution of the outcome variable (the random part of the model) to the systematic (explanatory) part of the model. For traditional linear models in which the outcome variable follows the normal distribution, the link function used is the identity link; it specifies that the expected value of the outcome variable is a linear combination of the $x$ 's. When the outcome variable follows a binomial distribution, link functions commonly used are the logit and probit, giving rise to logistic and probit regressions respectively.

\section{Binomial distribution with identity link}

The use of GLM with a binomially distributed dependent variable and specifying an identity link function in this non-linear context is a suitable choice in the decomposition analysis of a binary outcome because it considers the structure of the distribution while preserving the link between the independent and dependent variables. The decomposition requires an identity link for the mathematics in Equation 3 to hold. This can be calculated using the Stata command:glm y x, family (binomial) link(identity)[25].

\section{Results}

The overall concentration index for reported illness in the previous month in the Thai sample of 2003 was -0.105 (95\% confidence interval $-0.086,-0.124)$. Thus recent illness was concentrated more at the poorer end of the income distribution. Proportions in age-sex, education and geographic residence groups are presented in Table 1. Negative concentration indices showed lower socioeconomic status among males aged 60 or older $(C=-0.247)$ females aged 60 or older $(C=-0.251)$, persons with no education $(C=-0.321)$, and those residing in the Northeastern region $(\mathrm{C}=-0.256)$. We decomposed the overall inequality observed, estimating

Table 1 Proportions and concentration indices for age-sex, education and geographic groups

\begin{tabular}{|c|c|c|c|}
\hline Groups & & Proportion $\left(\bar{x}_{k}\right)$ & Concentration index $\left(C_{k}\right)^{*}$ \\
\hline \multicolumn{4}{|l|}{ Age-sex (years) } \\
\hline Males aged 15-29 & & 0.143 & 0.035 \\
\hline Males aged $30-44$ & & 0.144 & 0.080 \\
\hline Males aged 45-59 & & 0.103 & 0.049 \\
\hline Males aged $60+$ & & 0.061 & -0.247 \\
\hline Females aged 15-29 & & 0.170 & 0.024 \\
\hline Females aged 30-44 & & 0.176 & 0.059 \\
\hline Females aged 45-59 & & 0.123 & -0.009 \\
\hline Females aged 60+ & & 0.079 & -0.251 \\
\hline & Subtotal & 1.000 & \\
\hline \multicolumn{4}{|l|}{ Education levels } \\
\hline No education & & 0.055 & -0.321 \\
\hline Primary level & & 0.585 & -0.123 \\
\hline High school level & & 0.258 & 0.125 \\
\hline Higher level & & 0.101 & 0.570 \\
\hline & Subtotal & 1.000 & \\
\hline \multicolumn{4}{|l|}{ Regions } \\
\hline Bangkok & & 0.139 & 0.559 \\
\hline Central region & & 0.215 & 0.179 \\
\hline Northern region & & 0.195 & -0.162 \\
\hline Northeastern region & & 0.341 & -0.256 \\
\hline Southern region & & 0.110 & 0.024 \\
\hline & Subtotal & 1.000 & \\
\hline
\end{tabular}

Source: Thai Health and Welfare Survey 2003 
contributions due to age-sex, education and regions (Table 2). We used three estimates (OLS, marginal effects from probit analysis and GLM binomial identity) and compared results obtained with two extreme sets of reference groups (the most and least advantaged in each category). Each column presents contributions to the overall concentration index which are obtained from the first element in Equation 3 (i.e., Contribution to Concentration index or $\left.\mathrm{CC}=\frac{\beta_{k} \bar{x}_{k}}{\mu} C_{k}\right)$ as well as percentages of the overall concentration index (-0.105). Both the OLS and GLM binomial identity approaches gave CC subtotal estimates that did not vary by choice of reference groups, in marked contrast to the probit-based estimates.

Estimation using marginal effects from probit analysis sees the sum of the contributions to the overall concentration index $(\Sigma C C I)$ depending on the choice of reference groups, for which no guidance is given in literature that has used this approach. At the two extremes, in our example, choosing set 1 as reference groups tends to result in more of the observed inequality being explained $(\Sigma C C=-0.086$, or 82.0 percent of $C=-0.105)$, while choosing set 2 tends to result in appreciably less of it being explained ( $\Sigma C C=-0.061$, or 58.2 percent of $\mathrm{C}=-0.105)$. More generally, it would appear that one is likely to get a higher $\Sigma C C$ percent figure when reference groups are at the opposite extreme to the overall inequality.

\section{Discussion and conclusion}

There are two requirements for a satisfactory concentration index decomposition in a non-linear (binary outcome) setting: first, the binomial distribution of the outcome needs to be taken into account; and second, the outcome variable must be a linear combination of the independent determinants for the mathematics of the decomposition of the concentration index to hold. The OLS approach is based on a normal model with an identity link function and the probit approach is in essence a binary distribution with a probit link. The OLS approach should not be used for binary outcomes

Table 2 Contributions to Concentration indices (CC) and its percent contributions (shown in brackets) comparing two reference sets for Ordinary Least Squares (OLS), Probit and Generalized Linear Model (GLM) with binomial distribution and identity link

\begin{tabular}{|c|c|c|c|c|c|c|}
\hline Groups & $\begin{array}{c}\text { OLS (\%) } \\
\text { Reference 1* }\end{array}$ & $\begin{array}{c}\text { OLS (\%) } \\
\text { Reference } 2 *\end{array}$ & $\begin{array}{c}\text { Probit (\%) } \\
\text { Reference } 1\end{array}$ & $\begin{array}{c}\text { Probit (\%) } \\
\text { Reference } 2\end{array}$ & $\begin{array}{c}\text { GLM (\%) } \\
\text { Reference } 1\end{array}$ & $\begin{array}{c}\text { GLM (\%) } \\
\text { Reference } 2\end{array}$ \\
\hline Males 15-29 & ref & $-0.007(7.0)$ & ref & $-0.005(4.5)$ & ref & $-0.007(7.0)$ \\
\hline Males 30-44 & $0.002(-1.7)$ & $-0.015(14.6)$ & $0.003(-2.6)$ & $-0.010(9.3)$ & $0.002(-1.6)$ & $-0.015(14.6)$ \\
\hline Males 45-59 & $0.003(-2.4)$ & $-0.005(4.8)$ & $0.003(-3.2)$ & $-0.003(3.0)$ & $0.002(-2.3)$ & $-0.005(4.8)$ \\
\hline Males 60+ & $-0.016(15.2)$ & $0.006(-6.1)$ & $-0.020(18.7)$ & $0.004(-4.1)$ & $-0.016(15.1)$ & $0.006(-6.1)$ \\
\hline Females 15-29 & $0.001(-0.7)$ & $-0.005(5.1)$ & $0.001(-1.0)$ & $-0.004(3.4)$ & $0.001(-0.6)$ & $-0.005(5.1)$ \\
\hline Females 30-44 & $0.005(-4.7)$ & $-0.010(9.8)$ & $0.007(-6.3)$ & $-0.007(6.5)$ & $0.005(-4.5)$ & $-0.011(10.0)$ \\
\hline Females 45-59 & $-0.001(0.9)$ & $0.001(-0.7)$ & $-0.001(1.1)$ & $0.000(-0.5)$ & $-0.001(0.9)$ & $0.001(-0.7)$ \\
\hline Females 60+ & $-0.029(27.9)$ & ref & $-0.034(32.2)$ & ref & $-0.029(27.8)$ & ref \\
\hline Subtotal & $-0.036(34.5)$ & $-0.036(34.5)$ & $-0.041(39.0)$ & $-0.023(22.1)$ & $-0.037(34.7)$ & $-0.037(34.7)$ \\
\hline No education & $-0.005(4.6)$ & ref & $-0.005(5.0)$ & ref & $-0.004(3.4)$ & ref \\
\hline Primary & $-0.018(17.1)$ & $0.002(-1.6)$ & $-0.019(18.3)$ & $0.000(-0.3)$ & $-0.014(13.2)$ & $0.001(-0.7)$ \\
\hline High school & $0.002(-2.1)$ & $-0.007(6.3)$ & $0.002(-2.0)$ & $-0.007(6.2)$ & $0.001(-0.8)$ & $-0.006(5.4)$ \\
\hline Higher & ref & $-0.016(15.0)$ & Ref & $-0.015(14.0)$ & ref & $-0.012(11.2)$ \\
\hline Subtotal & $-0.021(19.7)$ & $-0.021(19.7)$ & $-0.022(21.3)$ & $-0.021(19.9)$ & $-0.017(15.9)$ & $-0.017(15.9)$ \\
\hline Bangkok & ref & $-0.039(37.0)$ & Ref & $-0.034(32.4)$ & ref & $-0.038(36.2)$ \\
\hline Central & $0.001(-1.3)$ & $-0.018(17.2)$ & $0.002(-1.9)$ & $-0.016(15.1)$ & $0.003(-2.4)$ & $-0.016(15.6)$ \\
\hline North & $-0.016(15.1)$ & ref & $-0.017(16.3)$ & ref & $-0.016(14.8)$ & ref \\
\hline Northeast & $-0.007(6.9)$ & $0.037(-34.7)$ & $-0.008(8.0)$ & $0.034(-31.9)$ & $-0.007(6.2)$ & $0.036(-34.5)$ \\
\hline South & $0.001(-0.6)$ & $-0.001(0.7)$ & $0.001(-0.7)$ & $-0.001(0.6)$ & $0.001(-0.6)$ & $-0.001(0.7)$ \\
\hline Subtotal & $-0.021(20.2)$ & $-0.021(20.2)$ & $-0.023(21.8)$ & $-0.017(16.1)$ & $-0.019(18.0)$ & $-0.019(18.0)$ \\
\hline$\Sigma C C$ & $-0.078(74.3)$ & $-0.078(74.3)$ & $-0.086(82.0)$ & $-0.061(58.2)$ & $-0.072(68.6)$ & $-0.072(68.6)$ \\
\hline Residual & $-0.027(25.7)$ & $-0.027(25.7)$ & $-0.019(18.0)$ & $-0.044(41.8)$ & $-0.033(31.4)$ & $-0.033(31.4)$ \\
\hline Overall C & -0.105 & -0.105 & -0.105 & -0.105 & -0.105 & -0.105 \\
\hline
\end{tabular}

Source: Thai Health and Welfare Survey 2003

*Reference values used in set 1 are: males aged 15-29, higher education, Bangkok.

*Reference values used in set 2 are: females aged $60+$, no education, North. 
because it does not meet the first requirement. And a probit estimate fails the second requirement because it produces estimates that depend on the choice of reference groups. In practice, it is also possible to estimate a marginal effect using the average of the individual effects rather than the average effect [2].

Decomposition of concentration indices yields useful information regarding the relative importance of various determinants of inequitable health outcomes. But the two decomposition estimation approaches in current use are not suitable for binary outcomes and such outcomes include many useful health indicators. In contrast, our GLM approach specifying the binomial distribution of the outcome and an identity link function allows the decomposition model to hold, and produces valid coefficient estimates that do not vary according to choice of reference groups. In addition the GLM binomial identity link is readily available in standard statistical packages like Stata, and thus should be a valid approach when decomposing concentration indices for binary outcomes.

\section{List of abbreviations}

GLM: Generalized Linear Model; OLS: Ordinary Least Squares; C: Concentration index; CC: Contributions of Concentration indices.

\footnotetext{
Acknowledgements

The study was conducted under the auspices of the overarching project "The Thai Health-Risk

Transition: a National Cohort Study", funded by the Wellcome Trust UK (GR071587 MA) and the Australian National Health and Medical Research Council (268055). We would like to thank the Thai National Statistical Office for the Health and Welfare Survey data and anonymous reviewers whose comments helped us improve this manuscript.
}

\section{Authors' contributions}

VY designed the study, analysed the data, and drafted the manuscript. LL was involved in the design of the study and the write-up of the manuscript. GC noticed that probit estimates were sensitive to the choice of reference groups and provided detailed comments and editorial guidance. KD provided conceptual advice. AS guided through to revisions and finalization of the manuscript. All authors read and approved the final version of the manuscript.

\section{Competing interests}

The authors declare that they have no competing interests.

Received: 3 November 2009 Accepted: 4 March 2010 Published: 4 March 2010

\section{References}

1. Kakwani N, Wagstaff A, van Doorslaer E: Socioeconomic inequalities in health: measurement, computation, and statistical inference. J Econom 1997, 77(1):87-103

2. van Doorslaer $E$, Koolman $X$, Jones AM: Explaining income-related inequalities in doctor utilisation in Europe. Health Econ 2004, 13(7):629-47.

3. Wagstaff $A$, Paci $P$, van Doorslaer $E$ : On the measurement of inequalities in health. Soc Sci Med 1991, 33(5):545-57.
4. Wagstaff $A$, Paci $P$, Joshi $\mathrm{H}$ : Causes of inequality in health: Who you are? Where you live? or Who your parents were? Policy Research Working Paper no. 2713 Washington DC: World Bank 2001.

5. Wagstaff A, van Doorslaer E, Watanabe N: On decomposing the causes of health sector inequalities with an application to malnutrition inequalities in Vietnam. J Econom 2003, 112:207-223.

6. Wildman J: Income related inequalities in mental health in Great Britain: analysing the causes of health inequality over time. J Health Econ 2003, 22(2):295-312.

7. van Doorslaer $E$, Koolman X: Explaining the differences in income-related health inequalities across European countries. Health Econ 2004, 13(7):609-28.

8. Hosseinpoor AR, Van Doorslaer E, Speybroeck N, Naghavi M, Mohammad K, Majdzadeh $\mathrm{R}$, et al: Decomposing socioeconomic inequality in infant mortality in Iran. Int J Epidemiol 2006, 35(5):1211-9.

9. Lee MC, Jones AM: Understanding differences in income-related health inequality between geographic regions in Taiwan using the SF-36. Health Policy 2007, 83(2-3):186-95.

10. Lauridsen J, Christiansen T, Gundgaard J, Hakkinen U, Sintonen H: Decomposition of health inequality by determinants and dimensions. Health Econ 2007, 16(1):97-102.

11. Gundgaard J, Lauridsen J: A decomposition of income-related health inequality applied to EQ-5D. Eur J Health Econ 2006, 7(4):231-7.

12. Nguyen $\mathrm{L}$, Hakkinen $\mathrm{U}$ : Income-related inequality in the use of dental services in Finland. Appl Health Econ Health Policy 2004, 3(4):251-62.

13. Blinder AS: Wage discrimination: reduced form and structural estimates. $J$ Hum Resour 1973, 8(4):436-455.

14. Oaxaca RL: Male-female wage differentials in urban labour markets. Intl Econ Rev 1973, 9:693-709.

15. Jones FL: On decomposing the wage gap: a critical comment on Blinder's method. J Hum Resour 1983, 18:126-130.

16. Oaxaca RL, Ransom MR: Identification in detailed wage decompositions. Rev Econs Stats 1999, 81:154-157.

17. Limwattananon S, Tangcharoensathien V, Prakongsai P: Catastrophic and poverty impacts of health payments: results from national household surveys in Thailand. Bull World Health Organ 2007, 85(8):600-6.

18. Kakwani $\mathrm{N}$ : Income inequality and poverty: methods of estimation and policy applications. New York: Oxford University Press 1980.

19. Wagstaff A: The bounds of the concentration index when the variable of interest is binary, with an application to immunization inequality. Health Econ 2005, 14(4):429-32.

20. Nelder JA, Wedderburn RWM: Generalized linear models. J R Stat Soc [Ser A] 1972, 135(3):370-384

21. O'Donnell O, van Doorslaer E, Wagstaff A, Lindelow M: Chapter 15: Measuring and explaining inequity in health service delivery. Analyzing Health Equity Using Household Survey Data Washington DC: World BankO'Donnell O, van Doorslaer E, Wagstaff A, Lindelow M 2007.

22. Greene WH: Econometric analysis. Upper Saddle River, N.J.: Prentice Hall, 5 2003

23. McCullagh P, Nelder JA: Generalized linear models. New York: Chapman and Hall 1983

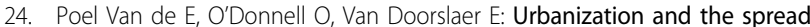
of diseases of affluence in China. Econ Hum Biol 2009, 7(2):200-16.

25. StataCorp: Intercooled Stata 9.0 for Windows. College Station TX: StataCorporation 2005

doi:10.1186/1756-0500-3-57

Cite this article as: Yiengprugsawan et al:: Decomposing socioeconomic inequality for binary health outcomes: an improved estimation that does not vary by choice of reference group. BMC Research Notes 2010 3:57. 